\title{
Changes in the timing of sexual intercourse in Ghana: evidence from the demographic and health survey data, 1988-20I4.
}

\section{Acheampong Yaw Amoateng \& Ololade Baruwa}

\author{
Population \& Health Research Entity, Faculty of Humanities, \\ North-West University (Mafikeng Campus) \\ South Africa
}

Email: yaw.amoateng@nwu.ac.za

\begin{abstract}
Background: Although sexuality is an inherent feature of humans, the timing of this important lifechanging event sets the tone for future sexual behaviour with broader social implications.

Data source \& Method: The present study used the six waves of the Ghana Demographic and Health Survey data (I988 to 20I4) to examine the effect of changes in social and demographic contexts on age at which women have their first sexual encounter.

Results: The results of the study have shown that even though the age at which women in Ghana initiate sexual intercourse is changing, the changes have been slow over the course of the 26 years under review (1988 to 2014). Of the social and demographers factors examined, only education, religion and ethnicity were found to be significant predictors of the timing of sexual intercourse among women in Ghana, while the effects of place of residence and region were found to be insignificant after controlling for other factors. Educated women tended to postpone the initiation of first sexual encounter compared to their less educated counterparts, while women who belonged to other Christian denominations and Muslims delayed sexual initiation compared to women who did not belong to any religious group. Finally, Ewes, Guans, Mole/Dagbanis and other ethnic groups all tended to delay sexual initiation compared to the majority Akan.

Conclussion: The study demonstrated that the timing of first sexual intercourse among women in Ghana is affected by social and demographic contexts such as place of residence, education, ethnicity, region, and religion.
\end{abstract}

Keywords: sexual intercourse; Ghana; education; ethnicity; demographic and health survey

\section{Introduction}

There has been considerable scholarly interest in adolescent sexual behaviour in recent years as judging by the number of articles dealing with various aspects of age at sexual debut. The first sexual initiation is a significant event for both the individuals involved and society at large. Although sexuality is an inherent feature of humans, the timing of this important lifechanging event sets the tone for future sexual behaviour with broader social implications. For example, the age at which a person has first sexual intercourse has been found to be associated with physical and mental health, sexually transmitted infections (STIs) and depression (Vasilenko, Kugler, \& Rice, 2016). Studies across sub-Saharan African countries have suggested that early sexual debutants are not likely to have ideas on how to prevent STIs, including HIV than those who delay sexual intercourse (Harrison, Xaba, \& Kunene, 200I; Zulu et al., 2002). Possible explanations of this situation maybe inability to negotiate condom use with a sexual partner, biological factors, and accumulated numbers of sexual partners due to longer years of sexual activities (Kaestle, 2005; Vasilenko et al., 2016).

Moreover, the timing of sexual intercourse has various adverse public health consequences that disproportionately affect both adolescents and adults (Sandfort, Orr, Hirsch, \& Santelli, 2008). The timing at which people experience their first sexual intercourse is very crucial given that age at first sexual intercourse is linked to risky sexual behaviours including multiple concurrent sexual partners, nonuse of condoms, exposure to sexually transmitted infections (STIs) unwanted pregnancy and teenage pregnancies among women (Magnusson et al., 20I5; Richter et al., 2015; Shrestha et al., 2016; Stephenson, Simon, \& Finneran, 2014; Tenkorang \& Owusu, 2013; Wellings \& Field, 1996; Zulu, Dodoo, \& Chika-Ezee, 2002). In sub-Saharan Africa, about $60 \%$ of young women had begun sexual activities before the age of 18 years (Stephenson et al., 2014). 
Moreover, a study found that late initiation of sexual intercourse is associated with sexual problems including arousal and orgasm which is most likely to occur among men than women, and also suggesting that both early and late timing of sexual initiation may be a risk of negative adult health outcomes (Sandfort et al., 2008).

\section{The present study}

Since early sexual debut is a good indicator of exposure to risk of pregnancy, sexually transmitted infections and other poor sexual health and risk behaviours patterns (de Irala et al., 20I I; Osorio et al., 20I7), knowing the age at which young people start having sexual intercourse is important for public health interventions that target the youth and discourage premarital sexual activity (Zaba et al., 2004). This is particularly important for a continent battling an HIV/AIDS pandemic, among other demographic trends. However, an exclusive focus on the risks associated with young people's sexual activity is not enough. The context within which the first sexual intercourse occurs is equally important for the design of effective preventative programs. While some studies have examined the correlates of timing and age at sexual debut especially among adolescent and young adults (Kaestle, 2005; Stephenson et al., 2014; Vasilenko et al., 2016), few have investigated the changes in timing of age at first sexual intercourse. Evidence pertaining to changes in timing of age at first sexual intercourse remains relatively scarce.

The present study aims to fill this knowledge gap by using a nationally population-based dataset of the Ghana Demographic and Health Survey to examine the changes in timing of sexual intercourse in Ghana from 1988-2014, specifically looking at the effect of educational attainment, ethnic identification, religious affiliation, place of residence, and region of residence. The findings from this study will provide inform policy and programme formulation as well as implementation to be specifically tailored at addressing timing of first sexual intercourse.

\section{Review of the empirical literature}

Individual-level factors found to be associated with early initiation of sexual activity include religion, ethnicity, place of residence/region and educational level. In their study of six African countries, Zaba et al. (2004) found both places of residence/region and educational level to influence the age at first sex, with both secondary education and urban residence associated with later age at first sex for both genders. In examining factors associated with sexual debut and early age at first sex among young men and women ( $12-25$ years) in a population with a high prevalence 4589 and incidence of HIV in rural South Africa, McGrath et al. (2009) found school attendance had a significant protective effect as it delayed sexual debut among both men and women. They also found that living in a more rural rather than urban area was associated with later age at first sex in men and women (McGrath et al., 2009).

As far as education is concerned, Stephenson et al. (20/4) found that the effects of education varied across genders and countries in their sample of adolescents in four African countries. For example, they found that education prolonged sexual debut in females with secondary education in Malawi and Uganda but this effect was not evident for females in Burkina Faso or Ghana. This is at odds with results from the 2014 Ghana Demographic and Health Survey that suggests that education has an effect on age at first sex, where Ghanaian women with no education are found to begin sexual activity 3.1 years earlier than their educated counterparts (GSS, 20I4). Nonetheless, these findings demonstrate that the effects of education tend to vary as there is no consensus on whether sexual debut increases or decreases with educational level. In some instances, being enrolled in school or having had an education is found to be associated with a reduced sexual activity, whilst in others, the converse is observed. Even so, the general observation is that better-educated young people begin sexual activity at a later age than those who are less-educated, albeit some inconsistencies found with respect to gender and urban-rural differences (Awusabo-Asare et al., 2004).

Similarly, religious values or religiosity have been found to be associated with the postponement of first sexual intercourse among young people in the US (Abbott \& Dalla, 2008), Kenya (Tenkorang \& Maticka-Tyndale, 2008), Nigeria (Envuladu et al., 20I7), and Ghana (Tenkorang \& Adjei, 20I5). These findings reinforce the notion of religion enforcing behavioural norms such as sexual abstinence. Moreover, McGrath et al.'s (2009) study of South African youth found religious affiliation significantly impacted sexual debut among women although not among men.

Ethnic influences also appear to shape young people's sexual behaviour, although results are inconclusive. For example, Upchurch et al. (1998) found significant ethnic differences in the timing of first sexual intercourse in an American sample. They found that African Americans reported younger age at first sex on average compared to Asian Americans. In contrast, Stephenson et al. (20l4) did not find ethnicity and religious affiliation to affect early initiation of sexual activity in any of their demographic group examined, with two exceptions: female adolescents in Burkina Faso not belonging to the 
majority religious group were more likely to initiate early sexual activity, and males in Malawi not belonging to the majority ethnic group were less likely to report early sexual activity. Ethnicity was found to be associated with the postponement of first sexual intercourse among upper primary school students in Kenya (Tenkorang \& Maticka-Tyndale, 2008). The present study uses the six waves of the Ghana Demographic and Health Survey data which spans the period 1988 to 2014 , to examine the effect of education, ethnicity, religion, region, and residence on changes in the age at sexual debut in Ghana across the six surveys.

\section{Data and methods}

The data source for this study were drawn from Ghana Demographic and Health Surveys (GDHS) from the individual files of women of reproductive ages, 15 to 49 years old for the survey periods 1988 , 1993, 1998, 2003, 2008 and 2014. The respective data contained data as follows: The 1988 sample contained data of 4488 individuals and 4406 households; the 1993 data contained 4562 individuals and 5919 households; the 1998 data contained 4843 individuals and 6375 households; the 2003 data contained 569I individuals and 625I households; the 2008 data contained 4916 individuals and 11778 households and the 2014 data contained data of 9396 individuals and II835 households. Among data collected across these surveys includes background characteristics such as education, ethnicity, religion, place of residence, region of residence, age at first sexual intercourse, age at first marriage or cohabitation, age at first birth, marital duration, total number of children ever born, health service providers, communities, household health expenditures of women as well as information on young adults.

The outcome variable for this study is age at first intercourse while the explanatory variable of interest are of educational attainment, ethnic identification, religious affiliation, place of residence, and region of residence. Median age at first sex was conducted using a graph in the descriptive analysis. To assess the changes in trend of median age at first sexual intercourse among women in Ghana, a two-way cross tabulation of median age at first sexual intercourse and the socio-demographic variables used in the study was conducted on each survey dataset. As for the multivariate analysis, a Cox proportional hazard regression analysis was performed and all data from 1988 - 2014 were pooled together to test the effect of place of residence, education, ethnicity, religion, and region timing of sexual intercourse among women in Ghana.

The most appropriate method for estimating the distribution of age at first sexual intercourse is survival analysis using Cox proportional hazard regression model. Cox proportional analysis model is used in this study to examine the effect of the sociodemographic factors of interest in this study on the age at which respondents first experienced sexual intercourse. We calculated survival functions describing the probability of respondents having sexual intercourse and those remaining without having sexual intercourse. Reported age at first sexual intercourse is the failure of event and those remaining without sexual intercourse are censored at their current age. All data were weighted and analysed using Stata 15 version.

\section{Results}

Table I presents the main characteristics of the respondents in each survey. Women living in rural areas of Ghana were in the majority in all the six surveys, whereas the proportion of women living in urban areas increased from $33.9 \%$ to $49 \%$ between $1988-2014$, except for the third survey (1998) where the rate dropped to $32.7 \%$ against $33.9 \%$ in the first survey (1988). With regards to education, Table I shows that there was a marked improvement in women's education in Ghana. For instance, women with tertiary education increased from $0.9 \%$ in 1988 to $5.5 \%$ in 2014 . With respect to religion, majority of the women in Ghana belonged to Other Christian group. For example, women who belonged to the Other Christian group constituted $53.1 \%$ in 1988 and by 2014 they comprised $62 \%$ of the sample. The majority of the women are from the Akan ethnic group. However, table I shows a decline in the population of women from Akan group from $53 \%$ in 1988 to $41.3 \%$ in 2014 . In terms of region, the Western region accounts for the lowest $(8.7 \%)$ women in all regions of Ghana 1988 while the Northern region accounts for the highest (28.5\%) women in all regions of Ghana in 2014. 
Table I: Socio-demographic characteristics of women age 15-49 years surveyed in demographic and health survey from 1988, 1993, 1998, 2003, 2008, and 2014

\begin{tabular}{|c|c|c|c|c|c|c|}
\hline & & & & & & \\
\hline Characteristics & $\begin{array}{l}1988 \\
n=4483\end{array}$ & $\begin{array}{l}1993 \\
n=4562\end{array}$ & $\begin{array}{l}1998 \\
n=4840\end{array}$ & $\begin{array}{l}2003 \\
n=569 \mid\end{array}$ & $\begin{array}{l}2008 \\
n=4916\end{array}$ & $\begin{array}{l}2014 \\
n=9394\end{array}$ \\
\hline \multicolumn{7}{|l|}{ Residence } \\
\hline Urban & $1523(33.9)$ & $1720(37.7)$ & $1585(32.7)$ & $2374(41.7)$ & $2162(44.0)$ & $4602(49.0)$ \\
\hline Rural & $2965(66.1)$ & $2842(62.3)$ & $3258(67.3)$ & $3317(58.3)$ & $2754(56.0)$ & $4794(51.0)$ \\
\hline \multicolumn{7}{|l|}{ Education } \\
\hline No Primary & $1783(39.7)$ & $1597(35.0)$ & $1737(35.9)$ & $1917(33.7)$ & $1243(25.3)$ & $228 \mid(24.3)$ \\
\hline Primary & $2369(52.8)$ & $2497(54.7)$ & $813(16.8)$ & $1112(19.5)$ & $1000(20.3)$ & $1747(18.6)$ \\
\hline Secondary & $296(6.6)$ & $396(8.7)$ & $2188(45.2)$ & $2518(44.3)$ & $2492(50.7)$ & $4854(5 । .7)$ \\
\hline Higher & $40 \quad(0.9)$ & $72(1.6)$ & $105(2.2)$ & $144(2.5)$ & $|8|(3.7)$ & $5 \mid 4(5.5)$ \\
\hline \multicolumn{7}{|l|}{ Ethnicity } \\
\hline Akan & $2379(53.0)$ & $2268(50.3)$ & $2240(46.3)$ & $2481(43.6)$ & $2136(43.5)$ & $3876(4 \mid .3)$ \\
\hline Ga/Adangbe & $397(8.9)$ & $364(8.1)$ & $344(7.1)$ & $437(7.9)$ & $309(6.3)$ & $519(5.5)$ \\
\hline Ewe & Ewe (16.0) & $679(15.1)$ & $646(13.3)$ & $698(12.3)$ & $637(13.0)$ & $1118(11.9)$ \\
\hline Guan & $104(2.3)$ & $99(2.2)$ & $71(1.5)$ & $159(2.8)$ & $117(2.4)$ & $256(2.7)$ \\
\hline Mole/Dagbani & $492(11.0)$ & $710(15.8)$ & $510(10.5)$ & $1119(19.7)$ & $107 \mid(2 \mid .8)$ & $2270(24.2)$ \\
\hline Others & $395(8.8)$ & $386(8.6)$ & $1032(21.3)$ & $797(14.0)$ & $646(13.1)$ & $1356(14.4)$ \\
\hline \multicolumn{7}{|l|}{ Religion } \\
\hline No religion & $531(11.8)$ & $538(11.8)$ & $340(7.0)$ & $302(5.3)$ & $178(3.6)$ & $273(2.9)$ \\
\hline Catholic & $765(17.1)$ & $821(18.0)$ & $775(16.0)$ & $905(15.9)$ & $733(14.9)$ & $134 \mid(14.3)$ \\
\hline Other Christian & $2381(53.1)$ & $2470(54.2)$ & $2724(56.3)$ & $3259(57.3)$ & $2897(77.5)$ & $5828(62.0)$ \\
\hline Muslim & $445(9.9)$ & $531(11.7)$ & $642(13.3)$ & $1013(17.8)$ & $832(16.9)$ & $1726(18.4)$ \\
\hline Traditional & $363(8.1)$ & $197(4.3)$ & $362(7.5)$ & $211(3.7)$ & $273(5.6)$ & $227(2.4)$ \\
\hline \multicolumn{7}{|l|}{ Region } \\
\hline Western & $392(8.7)$ & $398(8.7)$ & $519(10.7)$ & $524(9.2)$ & $438(8.9)$ & $1027(10.9)$ \\
\hline Central & $464(10.3)$ & $438(9.6)$ & $447(9.2)$ & $352(6.2)$ & $334(6.8)$ & $941(10.0)$ \\
\hline Greater/Accra & $598(13.3)$ & $618(13.6)$ & $692(14.3)$ & $835(14.7)$ & $692(14.1)$ & $999(10.6)$ \\
\hline Eastern & $703(15.7)$ & $519(11.4)$ & $550(11.4)$ & $506(8.9)$ & $479(9.7)$ & $907(9.7)$ \\
\hline Volta & $500(11.1)$ & $49 \mid(10.8)$ & $439(9.1)$ & $442(7.8)$ & $433(8.8)$ & $795(8.5)$ \\
\hline Ashanti & $823(18.3)$ & $750(16.4)$ & $629(13.0)$ & $927(16.3)$ & $815(16.6)$ & $1040(11.1)$ \\
\hline Brong/Ahafo & $500(11.1)$ & $469(10.3)$ & $309(6.4)$ & $638(11.2)$ & $403(8.2)$ & $1005(10.7)$ \\
\hline Northern & $508(11.3)$ & $879(19.3)$ & $1258(26.0)$ & $1467(25.8)$ & $1322(26.9)$ & $2682(28.5)$ \\
\hline
\end{tabular}

Trends and differentials in age at first sexual intercourse from $1988-2014$

The trends and differentials in the median age at first sexual intercourse and by selected sociodemographic characteristics of the women are presented in Figure I and Table 2 respectively. Figure
I shows that the median age at first intercourse increased from 16 years in 1988 to 17 years in 1993. The median age at first sexual intercourse remained at 17 years till 2008 before it increased to 18 years in 2014 . 
Figure I: Median age at first sexual intercourse among women in Ghana from 1988- 20I4

\section{Median age at first sexual intercourse in Ghana 1988-2014}

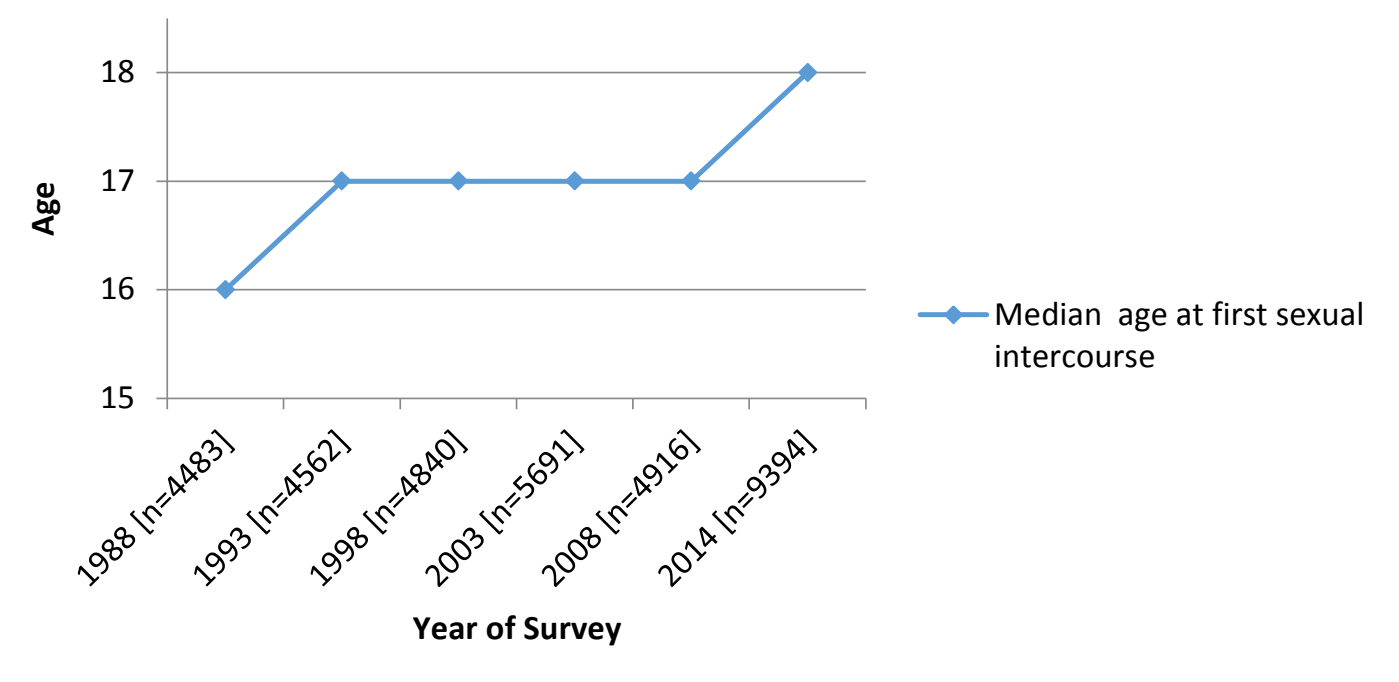

An examination of the socio-demographic characteristics of women in Ghana as shown in Table 2 reveals that with little exception, the trends in age at first sexual intercourse have followed the same general pattern across place of residence, education, ethnicity, religion and region. With regards to place of residence, the median age at first sexual intercourse in urban areas of Ghana increased from 16 years from 1988 to 17 years in 1993, 1998 and 2003. Further increase was observed in 2008 and 2014 where the median age at first sex was 18 years. The results in Table 2 show that the median age at first sexual intercourse among women living in rural areas was 16 years in 1988, 17 years in 1993 and 1998. A year increase was observed in 2003 where age at first sexual intercourse increased to 18 years. However, median age at first sexual intercourse decreased to 17 years in 2008 and later increased back to I8years in 2014.

From Table 2, we observe that education impacted age at first sexual intercourse positively although inconsistently. On the whole, Table 2 shows that age at first sexual intercourse continued to increase with improved education across the survey years. However, the inconsistent impact of education on age at first sexual intercourse is observed in 2003 where the median age at first sexual intercourse for women with no education was 18 years, women with primary and secondary education was 17 years and women with tertiary education was 18 years. The results also show that women with tertiary education increased from 17 years 1988 to 18 years in 1993 and 1998. It further increased to 19 years in 2003 and then to 20 years in 2014 .

http://aps.journals.ac.za
As far as the effect of ethnicity on age at first sexual intercourse is concerned, Table 2 shows that there was no difference in age at first sexual intercourse in all ethnic groups in 1988. However, minor differences were observed in all other years of the survey. For example, the median age at first sexual intercourse was 16 years across all ethnic groups in 1988. However, by 2008 the median age at first sexual intercourse was 17 years among women of the Akan, Ga/Adangbe and Ewe ethnic groups, while the median age at first sexual intercourse was 18 years among women of the Mole/Dagbani and Other ethnic groups. Also, Table 2 shows that the median age at first sexual intercourse inconsistently changed from 1988 to 2014 among the ethnic groups in Ghana. For instance, the median age at first sexual intercourse among women who belonged to the Guan ethnic group was 16 years in 1988, and increased to 17 years in 1993, 1998, and 2003 and then dropped to 16 years in 2008 and again increased to 18 years in 2014 .

With respect to religion, the results in table 2 show that there was no difference in all categories of religion in 1988 survey. However, minor differences were observed in the other survey years. For example, in the 2008 survey, median age at first sexual intercourse among women that professed no religion, Catholics, and other Christians was 17 years, while the median age at first sex among Muslims and Traditional religionists were 18 years. The trend in median age at first sexual intercourse did not consistently increase for all categories of religion except for the category "other religion" where the median age at first sexual intercourse increased from 
16 years in 1988, 1993, and 1998 to 17 years in 2003 and 2008 and then later increased to 18 years in 2014.

Age at first sexual intercourse varies with respect to administrative regions in Ghana. For instance, Table 2 shows that age at first sexual intercourse was 17 years among women living the Eastern, Volta, and
Brong/Ahafo regions in 20l4. Age at first sexual intercourse was 18 years for women in the Western, Central, Greater Accra and Ashanti region in 2014 while the median age at first sexual intercourse was 19 years for women living in the Northern region in 2014.

Table 2: Differentials in median age at first sexual intercourse and socio-demographic characteristics among women age $15-49$ years

\begin{tabular}{|c|c|c|c|c|c|c|}
\hline Characteristics & $\begin{array}{l}1988 \\
n=4483\end{array}$ & $\begin{array}{l}1993 \\
n=4562\end{array}$ & $\begin{array}{l}1998 \\
n=4840\end{array}$ & $\begin{array}{l}2003 \\
n=5691\end{array}$ & $\begin{array}{l}2008 \\
n=4916\end{array}$ & $\begin{array}{l}2014 \\
\mathrm{n}=9394\end{array}$ \\
\hline \multicolumn{7}{|l|}{ Residence } \\
\hline Urban & 16 & 17 & 17 & 17 & 18 & 18 \\
\hline Rural & 16 & 17 & 17 & 18 & 17 & 18 \\
\hline \multicolumn{7}{|l|}{ Education } \\
\hline No Primary & 16 & 18 & 19 & 18 & 19 & 16 \\
\hline Primary & 16 & 16 & 16 & 17 & 16 & 17 \\
\hline Secondary & 17 & 17 & 16 & 17 & 17 & 17 \\
\hline Higher & 17 & 18 & 18 & 19 & 20 & 20 \\
\hline \multicolumn{7}{|l|}{ Ethnicity } \\
\hline Akan & 16 & 16 & 16 & 17 & 17 & 18 \\
\hline $\mathrm{Ga} /$ Adangbe & 16 & 17 & 17 & 17 & 17 & 18 \\
\hline Ewe & 16 & 16 & 17 & 17 & 17 & 18 \\
\hline Guan & 16 & 17 & 17 & 17 & 16 & 18 \\
\hline Mole/Dagbani & 16 & 19 & 17 & 19 & 18 & 19 \\
\hline Others & 16 & 18 & 19 & 17 & 18 & 18 \\
\hline \multicolumn{7}{|l|}{ Religion } \\
\hline No religion & 16 & 17 & 18 & 18 & 17 & 19 \\
\hline Catholic & 16 & 17 & 17 & 17 & 17 & 18 \\
\hline Other Christian & 16 & 16 & 16 & 17 & 17 & 18 \\
\hline Muslim & 16 & 19 & 18 & 18 & 18 & 19 \\
\hline Traditional & 16 & 18 & 17 & 20 & 18 & 20 \\
\hline \multicolumn{7}{|l|}{ Region } \\
\hline Western & 15 & 16 & 16 & 17 & 17 & 18 \\
\hline Central & 16 & 17 & 17 & 17 & 17 & 18 \\
\hline Greater/Accra & 16 & 17 & $1 \cdot 7$ & 17 & 18 & 18 \\
\hline Eastern & 15 & 17 & 16 & 17 & 17 & 17 \\
\hline Volta & 15 & 16 & 17 & 17 & 17 & 17 \\
\hline Ashanti & 16 & 16 & 16 & 17 & 17 & 18 \\
\hline Brong/Ahafo & 15 & 16 & 16 & 17 & 17 & 17 \\
\hline Northern & 16 & 18 & 16 & 19 & 18 & 19 \\
\hline
\end{tabular}

\section{Multivariate Analysis}

The results of the multivariate analysis are presented in Table 3. The unadjusted hazard of age at first sexual intercourse is significantly lower among women residing in rural areas compared to those living in urban areas of Ghana (HR: 1.9, p-value $=0.00$ ). After adjusting for other variables used in the study, there is no significant difference between urban and rural areas of Ghana.

With respect to education of women, the unadjusted hazard of age at first sexual intercourse shows that women who had primary and secondary education have I.45 and I.27 times the hazard of early sexual initiation compared to women without formal 
education. On the other hand, the unadjusted hazard ratio shows that women with tertiary education have 0.97 times lower risk of early sexual initiation. After adjusting for all the variables in the model, women with primary and secondary education have 1.19 and 1.03 times the hazard of early sexual initiation compared to women without education, while women with tertiary education have 0.80 lower hazard risk of early sexual initiation compared with women with no education.

As far as ethnicity goes, only the hazard for Guan, Mole/Dagbani and Other women are found to be significant with timing of sexual intercourse. For example, Women from the Guan, Mole/Dagnani and Other ethnic groups have 0.92, 0.63, and 0.7I respectively lower hazard risk of early sexual initiation compared to women from the majority Akan ethnic group. However, after adjusting for all the other factors in the model, the Guan ethnic group is rendered insignificant while the hazard for the Ewe ethnic group is significant. The result shows that women from Ewe, Mole/Dagbani and Other ethnic groups have respectively $0.95,0.78$ and 0.82 lower the hazard risk of early sexual initiation compared to women from Akan ethnic group.

In terms of religion, Table 3 shows that women who belong to the other Christian group significantly have 1.06 times higher risk of early sexual initiation compared to women with no religion. While women who are Muslim significantly have 0.74 times lower the hazard or early sexual initiation compared to women who have no religion. And adjusting for other variables in the model, the results show that both other Christians and Muslim women significantly have lower hazard risk (HR: 0.92, $\mathrm{Cl}=0.88-0.97)$ and (HR: $0.88, \mathrm{Cl}=0.83-0.93$ ) respectively of early sexual initiation compared to no religion women in Ghana.

The unadjusted hazard ratio of women's region from Table 3 shows that women from the Eastern and Volta regions significantly have I.24 and I.II higher hazard of early sexual initiation compared to women from the Western region. Moreover, Table 3 shows that women from the Northern region have 0.65 lower hazard risk of early sexual initiation compared to women from the Western region. After adjusting for the presence of other variables used in the study, the direction of the result remains the same with slight differences in the magnitude of the hazard ratio. Specifically, women from the Eastern and Volta regions significantly have 1.23 and 1.13 higher hazard of early sexual initiation compared to women from the Western region, while women from Northern region have lower (HR: $0.82, \mathrm{Cl}=0.78$ 0.87 ) lower hazard risk of early sexual initiation compared to women from the Western region.

Table 3: Unadjusted and adjusted Hazard risk of age at first sexual intercourse using Demographic and Health Survey from 1988-2014

\begin{tabular}{|c|c|c|c|c|}
\hline & \multicolumn{2}{|c|}{ Unadjusted Hazard risk } & \multicolumn{2}{|c|}{ Adjusted Hazard risk } \\
\hline & $\mathrm{HR}$ & $\mathrm{Cl}$ & $\mathrm{HR}$ & $\mathrm{Cl}$ \\
\hline \multicolumn{5}{|l|}{ Characteristics } \\
\hline \multicolumn{5}{|l|}{ Residence } \\
\hline Urban & $\mathrm{I}$ & & 1 & \\
\hline Rural & 0.96 & $0.94-0.98^{*}$ & 1.00 & $0.97-1.03$ \\
\hline \multicolumn{5}{|l|}{ Education } \\
\hline No Primary & $\mathrm{I}$ & & 1 & \\
\hline Primary & 1.45 & I.40-I.49* & 1.19 & $1.15-1.23 *$ \\
\hline Secondary & 1.27 & I.23-I.30* & 1.03 & $1.00-1.07 *$ \\
\hline Higher & 0.97 & $0.91-1.03$ & 0.80 & $0.75-0.86 *$ \\
\hline \multicolumn{5}{|l|}{ Ethnicity } \\
\hline Akan & I & & 1 & \\
\hline $\mathrm{Ga} /$ Adangbe & 1.02 & $0.98-1.07$ & 1.00 & $0.95-1.05$ \\
\hline Ewe & 1.02 & $0.98-I .05$ & 0.95 & $0.91-0.99 *$ \\
\hline Guan & 0.92 & $0.85-0.99 *$ & 0.98 & $0.90-1.06$ \\
\hline Mole/Dagbani & 0.63 & $0.6 I-0.65 *$ & 0.78 & $0.74-0.82 *$ \\
\hline Others & 0.71 & $0.68-0.74 *$ & 0.82 & $0.78-0.86^{*}$ \\
\hline \multicolumn{5}{|l|}{ Religion } \\
\hline No religion & I & & I & \\
\hline Catholic & 1.02 & $0.97-1.08$ & 0.98 & $0.92-1.03$ \\
\hline Other Christian & 1.06 & I.0I-I.II* & $0.92-$ & $0.88-0.97 *$ \\
\hline
\end{tabular}




\begin{tabular}{|l|l|l|l|l|}
\hline Muslim & 0.74 & $0.70-0.79 *$ & 0.88 & $0.83-0.93^{*}$ \\
\hline Traditional & 0.84 & $0.78-0.90$ & 0.98 & $0.91-1.05$ \\
\hline Region & & & & \\
\hline Western & $\mathrm{I}$ & & $\mathrm{I}$ & \\
\hline Central & $\mathrm{I} .00$ & $0.95-\mathrm{I} .05$ & 0.98 & $0.94-\mathrm{I} .04$ \\
\hline Greater/Accra & 0.99 & $0.94-\mathrm{I} .03$ & $\mathrm{I} .03$ & $0.98-\mathrm{I} .08$ \\
\hline Eastern & $\mathrm{I} .24$ & $\mathrm{I} .18-\mathrm{I} .30^{*}$ & $\mathrm{I} .23$ & $\mathrm{I} .17-\mathrm{I} .29^{*}$ \\
\hline Volta & $\mathrm{I} . \mathrm{II}$ & $\mathrm{I} .05-\mathrm{I} .17^{*}$ & $\mathrm{I} .13$ & $\mathrm{I} .06-\mathrm{I} .20^{*}$ \\
\hline Ashanti & 0.99 & $0.94-\mathrm{I} .03$ & $\mathrm{I} .0 \mathrm{I}$ & $0.97-\mathrm{I} .06$ \\
\hline Brong/Ahafo & $\mathrm{I} .05$ & $0.99-\mathrm{I} .10$ & $\mathrm{I} .09$ & $\mathrm{I} .03-\mathrm{I} .15^{*}$ \\
\hline Northern & 0.65 & $0.62-0.68^{*}$ & 0.82 & $0.78-0.87^{*}$ \\
\hline
\end{tabular}

\section{Discussion and conclusion}

Even though as a public health issue, the initiation of sexual intercourse by women has always been of concern to both public health professionals and policymakers alike, in recent years the timing of this event such has become a major concern because of its implications for physical and mental health, sexually transmitted infections and depression. Because the timing of sexual initiation is variable depending on variation in the social and demographic conditions prevailing in society at any given time, effective policy interventions are based on knowledge of how varied social and demographic factors affect its timing.

In view of the fact that the evidence on how changing social and demographic contexts affect the timing of the age at sexual intercourse is thin in subSaharan Africa, this study sought to unpack the effect of changes in socio-demographic conditions on the timing of sexual intercourse among women in Ghana. The results of the study have shown that even though the age at which women in Ghana initiate sexual intercourse is changing, the changes have been slow over the course of the 26 years under review (1988 to 20I4). Specifically, the study's results have shown that the median age at first sexual intercourse increased in the 1990s compared to the 1980s but it remained stable between 1993 and 2008 and thereafter increased in 2014.

We found that while region of residence impacts the timing of the initiation of sexual intercourse in Ghana, after controlling for the relevant factors the effect of place of residence disappears. In terms of education, we found that there is a positive association between education and age at first sexual encounter. Specifically, women with primary or higher education, delay the onset of sexual intercourse compared with their counterparts without any education. This finding is consistent with the findings of Awusabo-Asare et al., (2004) on the study of adolescents' sexual and reproductive health in Ghana" which reported that women with better education delayed sexual intercourse to an older stage in life compared to less educated women who began sexual activity at a tender age. However, Stephenson et al. (2014) in a study of four subSaharan African countries found that the effect of education was not noticeable on timing of sexual intercourse in Burkina Faso and Ghana.

Religion and ethnicity are important factors that affect the timing of sexual intercourse in Ghana. We found that women who belong to other Christian groups and Muslims tend to delay sexual initiation compared to women who have no religion. This finding corroborates that of Mberu \& White (20II), who found that religion and ethnicity are few of the major factors that engender early sexual initiation. However, contrary to our study Mberu \& White (20II) found that Christian youths are more likely to initiate early sexual activities. On the effect of ethnicity on the timing of sexual intercourse, we found that Ewes, Guans, Mole/Dagbanis and other ethnic groups, initiate sexual intercourse later than the majority Akan. This finding is also similar to Mberu \& White (20II) findings in a study conducted in Nigeria that found substantial variations in sexual initiation across ethnic groups in Nigeria. In conclusion, the present study has demonstrated that the timing of first sexual intercourse among women in Ghana is affected by the social and demographic contexts.

\section{Study's limitations}

This study should not be interpreted without considering some limitations. A clear limitation of this study is the cross-sectional nature of the design which makes it difficult to assume causality with some of the variables examined. Another limitation to be considered is on the basis of the questionnaires as regards to socio desirability. Social desirability might have lowered the reporting or give rise to incorrect response of age at first sexual intercourse from the questionnaire. The sample size from the surveys examined exhibit little difference in all the years of 
survey except for 2014 survey where the sample size is larger compared to the previous years. Therefore, the sample of respondents observed in each survey may limit the extent to which the changes in sexual initiation over time can be vividly seen. Lastly, the population size of Akan region may affect the results on region and sexual initiation because the population size of the respondents in Akan comprised about half of the study sample size.

But, despite these limitations, this study contributes to the body of knowledge on timing of sexual intercourse in many ways. First, the study used a nationally representative sample which can be generalized to the population of Ghana. Second, the use of the survival analysis method by the study is appropriate in view of the dynamic nature of the phenomenon is sought to understand.

\section{References}

Abbott, DA \& Dalla, RL (2008) 'It's a choice, simple as that': youth reasoning for sexual abstinence or activity, Journal of Youth Studies, 11:6, 629649.

Abma, J; Driscoll, A \& Moore, K (1998) Young Women's Degree of Control over First Intercourse: An Exploratory Analysis, Family Planning Perspectives, 30:I, I2-18.

Awusabo-Asare, K; Abane, AM \& Kumi-Kyereme, A (2004) Adolescent Sexual and Reproductive Health in Ghana: A Synthesis of Research Evidence, Occasional Report,

New York: The Alan Guttmacher Institute, 2004, No. 13.

De Irala, J; Osorio, A; Carlos, S; Ruiz-Canela, M \& Lo' pez-del Burgo, C (20I I) Mean Age of First Sex: Do They Know What We Mean? Arch Sex Behav, 40, 853-855.

Envuladu, EA; Van de Kwaak, A; Zwanikken, P \& Zoakah, Al (20I7) Exploring the Factors Influencing Adolescent Sexual Behavior in Plateau State Nigeria, American Journal of Medicine and Medical Sciences, 7:I, I-6.

Ghana Statistical Service (GSS), Ghana Health Service (GHS), and ICF International (20I5) 2014 Ghana Demographic and Health Survey (DHS) Key Findings. Rockville, Maryland, USA: GSS, GHS, and ICF International.

Guo, W., Wu, Z., Qiu, Y., Chen, G., \& Zheng, X. (2012). The Timing of Sexual Debut Among Chinese Youth. International Perspectives on Sexual and Reproductive Health, 38(4), 196-204.

Harrison, A., Xaba, N., \& Kunene, P. (200I). Understanding safe sex: gender narratives of HIV and pregnancy prevention by rural South African school-going youth. Reproductive Health Matters, $9(\mid 7), \quad 63-7 \mid . \quad$ https://doi.org//0.1016/S09688080(0I)90009-6

Kaestle, C. E. (2005). Young Age at First Sexual Intercourse and Sexually Transmitted Infections in Adolescents and Young Adults. American Journal of Epidemiology, $161(8), \quad$ 774-780. https://doi.org//0.1093/aje/kwi095

Mberu, B. U., \& White, M. J. (20II). Internal Migration and Sexual Initiation among Never Married Youths in Nigeria. Social Science \& Medicine (1982), 72(8), 1284-| 293. https://doi.org/I0.1016/j.socscimed.201 I.02.019

McGrath, N; Nyirenda, M; Hosegood, V \& Newell, M-L (2009) Age at first sex in rural South Africa, Sex Transm Infect, 85(Suppl I), i49-i55.

Osorio, A; Lopez-del Burgo, C; Carlos, S \& de Irala, J (2017) The Sooner, the Worse? Association between Earlier Age of Sexual Initiation and Worse Adolescent Health and Well-being Outcomes, Front. Psychol., 8, 1298.

Richter, L; Mabaso, M; Ramjith, J \& Norris, SA (2015) Early sexual debut: Voluntary or coerced? Evidence from longitudinal data in South Africa the Birth to Twenty Plus study, S Afr Med J, 105:4, 304-307.

Sandfort, T. G. M., Orr, M., Hirsch, J. S., \& Santelli, J. (2008). Long-Term Health Correlates of Timing of Sexual Debut: Results From a National US Study. American Journal of Public Health, 98(I), I55I6I. https://doi.org/I0.2 I05/AJPH.2006.097444

Shrestha, R; Karki, P \& Copenhaver, M (2016) Early Sexual Debut: A Risk Factor for STIs/HIV Acquisition Among a Nationally Representative Sample of Adults in Nepal, Community Health, 4I:I, 70-77.

Stephenson, R., Simon, C., \& Finneran, C. (20/4). Community Factors Shaping Early Age at First Sex among Adolescents in Burkina Faso, Ghana, Malawi, and Uganda. Journal of Health, Population, and Nutrition, 32(2), I6I-I75.

Tenkorang, E. Y., \& Owusu, Y. A. (20I3). Coerced First Sexual Intercourse Among Women in Ghana: Evidence from the Demographic and Health Survey. Sexuality \& Culture, I7(I), 167-184. https://doi.org/|0.1007/s | 2 I | 9-012-9|46-I

Upchurch, DM; Levy-Storms, L; Sucoff, CA. \& Aneshensel, CS. (1998) Gender and Ethnic Differences in Timing of First Sex, Family Planning Perspectives, 30:3, I2I-I 27.

Vasilenko, S. A., Kugler, K. C., \& Rice, C. E. (2016). Timing of First Sexual Intercourse and Young Adult Health Outcomes. Journal of Adolescent Health, 59(3), 291-297. https://doi.org//0.1016/j.jadohealth.2016.04.019 
Wellings, K \& Field, B (1996) Sexual behaviour in young people, Bailliere's Clinical Ob Gy,

10 , I39-160.

Zaba, B; Pisani, E; Slaymaker, E \& Ties Boerma, J (2004) Age at first sex: understanding recent trends in African demographic surveys, Sex Transm Infect, 80(Suppl II), ii28-ii35.

Zulu, E. M., Dodoo, F. N.-A., \& Chika-Ezee, A. (2002). Sexual risk-taking in the slums of Nairobi, Kenya, 1993-8. Population Studies, 56(3), 31I323. https://doi.org//0.1080/003247202I5933 